\title{
Plasmacytoma of the Thyroid
}

\author{
Hakan Kaya $^{1^{*}}$, Tülay Tecimer ${ }^{2}$, İlker Ersözlü̈ ${ }^{3}$, Serdar Giray ${ }^{4}$ and Mete Düren ${ }^{5}$ \\ ${ }^{1}$ Department of Endocrine Surgery, Maslak Acibadem Hospital, Istanbul, Turkey \\ ${ }^{2}$ Department of Pathology, Acibadem University, Istanbul, Turkey \\ ${ }^{3}$ Department of Pathology, Maslak Acibadem Hospital, Istanbul, Turkey \\ ${ }^{4}$ Department of Surgery, Florence Nightingale Hospital, Istanbul, Turkey \\ ${ }^{5}$ Department of Endocrine Surgery, Maslak Acibadem Hospital, Istanbul, Turkey
}

\begin{abstract}
Plasmacytomas arise from plasma cells and are part of a family of plasma cell neoplasms. Extramedullary plasmacytomas are usually located in the upper respiratory tract and oral cavity. Thyroid involvement is rare and can be solitary or secondary to systemic multiple myeloma and constitutes less than $5 \%$ of all plasma cell neoplasms and $1.4 \%$ of extramedullary plasmacytomas. Fine needle aspiration biopsy may falsely predict medullary thyroid cancer or follicular neoplasm of Hurthle cells. Since plasma cells in thyroid are rare, such a finding in frozen section should raise a suspicion of plasma cell neoplasm. Here we report a case presenting with a $4 \mathrm{~cm}$ firm nodule in the thyroid. Fine needle aspiration biopsy was not diagnostic. Pathologic examination of the surgical specimen revealed an extramedullary plasmacytoma located in the thyroid. The association of solitary EMP of the thyroid gland with lymphocytic thyroiditis is known and 82\% of patients show lymphocytic thyroiditis as was the case with our patient. Clinical outcome of patients with localized disease is favorable. 10 -year overall survival rate is $70 \%$. The disease may progress to multiple myeloma in $11-30 \%$ of patients. Surgery and/or radiotherapy are the treatment of choice for these patients. Follow-up is required for disease progression and development of multiple myeloma.
\end{abstract}

\section{Introduction}

Plasmacytomas arise from plasma cells and are part of a family of plasma cell neoplasms which include monoclonal gammopathy of undetermined significance, multiple myeloma (MM), solitary plasmacytoma of bone and monoclonal immunoglobulin deposition diseases $[1,2]$. Extramedullary plasmacytomas are generally seen in the upper respiratory tract and oral cavity. While thyroid involvement may occur in the case of a multiple myeloma, solitary extramedullary plasmacytoma (SEP) of the thyroid is rare [3]. The disease in this patient group may progress to MM and patients should be followed. Here we report a case of a solitary extramedullary plasmacytoma of the thyroid.

\section{Case report}

A 46-year-old male patient admitted to our clinic for a lump in the neck. A firm, painless nodule was palpated in the right lobe of the thyroid. He had a history of lymphocytic thyroiditis and was using L-Thyroxin for hypothyroidy. There were no significant findings in the laboratory tests. Ultrasound imaging of the gland demonstrated a $4 \mathrm{~cm}$ nodule in the right lobe. Fine needle aspiration (FNA) biopsy of the nodule revealed atypical cells. Bilateral total thyroidectomy was recommended since the patient was on a hormone replacement regiment. But the patient insisted on sparing the contralateral lobe. Unilateral thyroidectomy was planned for the patient. Surgical exploration of the neck revealed a firm, white-gray nodule in the right lobe. Frozen section examination reported a nodule highly suspicious for papillary cancer on a lymphocytic thyroiditis background. So bilateral total thyroidectomy was performed. Postoperative period was uneventful, and the patient was discharged from the hospital on the first postoperative day.
Histopathologic examination of the right lobe showed a $4 \mathrm{~cm}$ nodule (Figure 1) and an accompanying papillary cancer on both lobes. The 4 $\mathrm{cm}$ nodule consisted of monotonous cells with middle-sized cytoplasm and eccentric nucleus which is may be seen in medullary thyroid cancer and Hurthle cell neoplasms. Amyloid and calcitonin staining were negative. Also, thyroglobulin, TTF-1 and cytokeratin were negative ruling out epithelial thyroid lesions. Immunohistochemistry analysis was positive for CD138, CD38, CD20 with kappa light restriction, but negative for lambda light chains (Figure 2), PAX5 and CD45. Ki-67 showed as low proliferation rate (15\%).

\section{Discussion}

Plasmacytoma of the thyroid is a rare entity and constitutes less than $5 \%$ of all plasma cell neoplasms and $1.4 \%$ of extramedullary plasmacytomas (EMP) [1,4]. Patients are predominantly middleaged males [5]. SEP is usually seen in the upper respiratory tract and oral cavity ( $80-90 \%$ of cases) which is usually encountered in more aggressive forms of the disease [6,7]. Thyroid involvement in multiple myeloma may occur but SEP of the thyroid is rare. So, MM should be ruled out which requires bone marrow biopsy, absence of osteolytic lesions and absence of monoclonal immunoglobulins.

The criteria for solitary extramedullary plasmacytoma are as follows [8]:

${ }^{*}$ Correspondence to: Hakan Kaya, Department of Endocrine Surgery, Maslak Acibadem Hospital, Istanbul, Turkey, E-mail: hakaya@outlook.com

Received: February 09, 2021; Accepted: February 19, 2021; Published: February 22,2021 


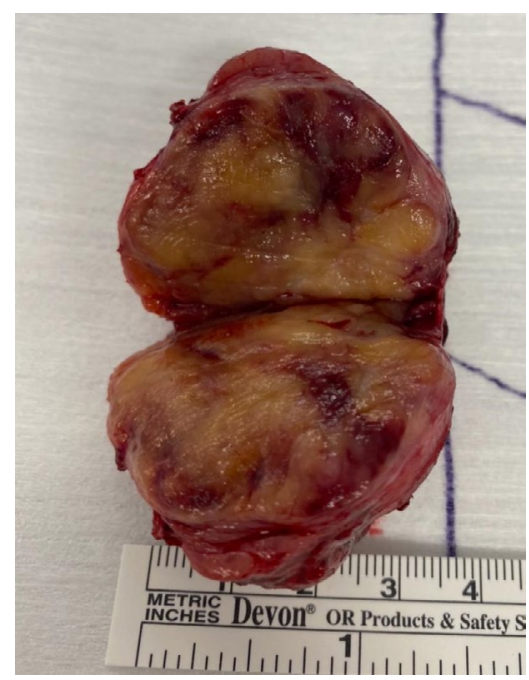

Figure 1. Macroscopy

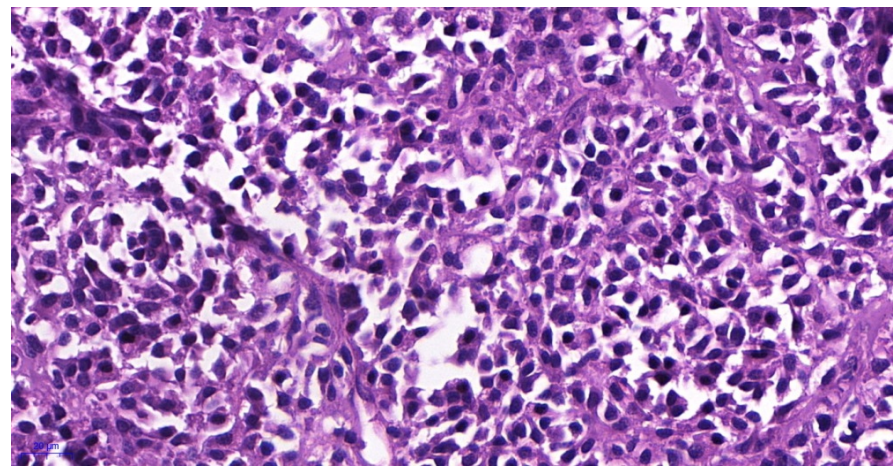

Figure 2a. Neoplasm consisted of monotonous plasma cells with middle-sized cytoplasm and eccentric nucleus. HE X400

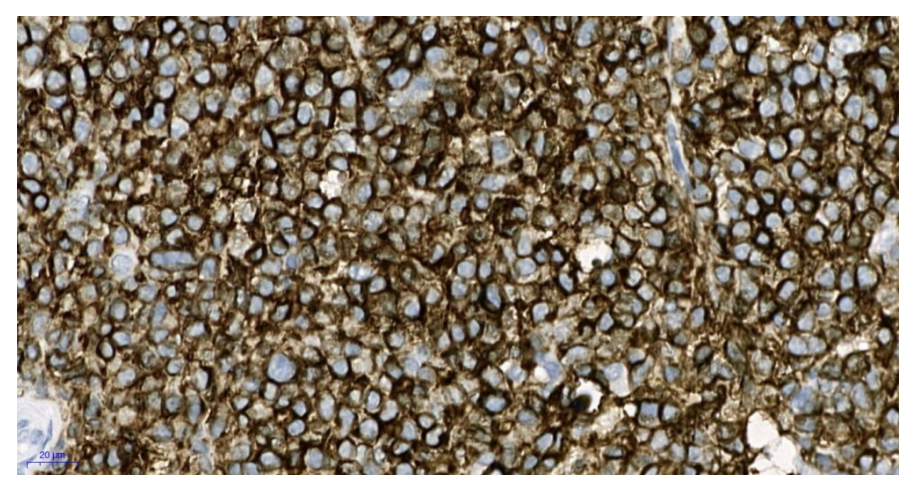

Figure 2b. CD $38 \times 40$

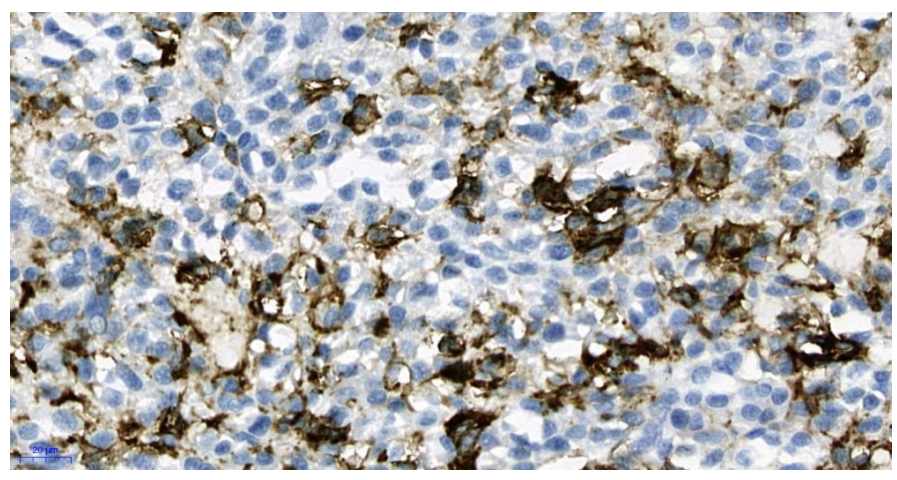

Figure 2c. 2c- CD20 positive cells have plasmacytoid morphology. CD20X40

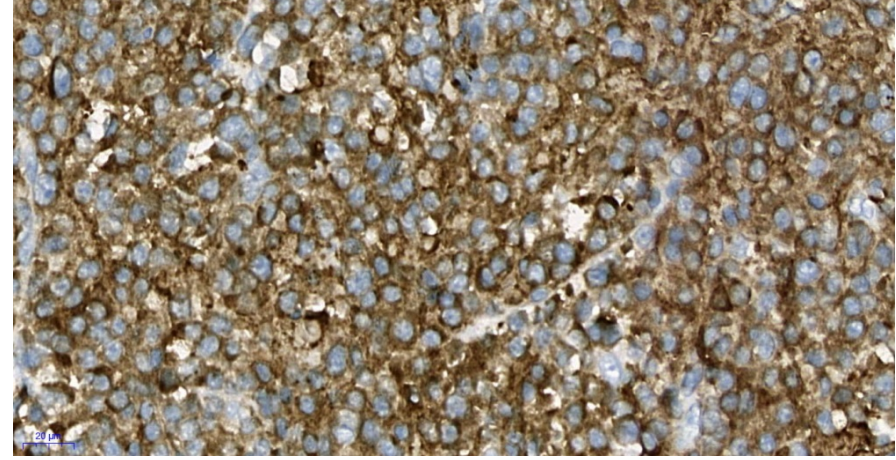

Figure 2d. Diffuse staining of neoplastic cells with kappa. X40

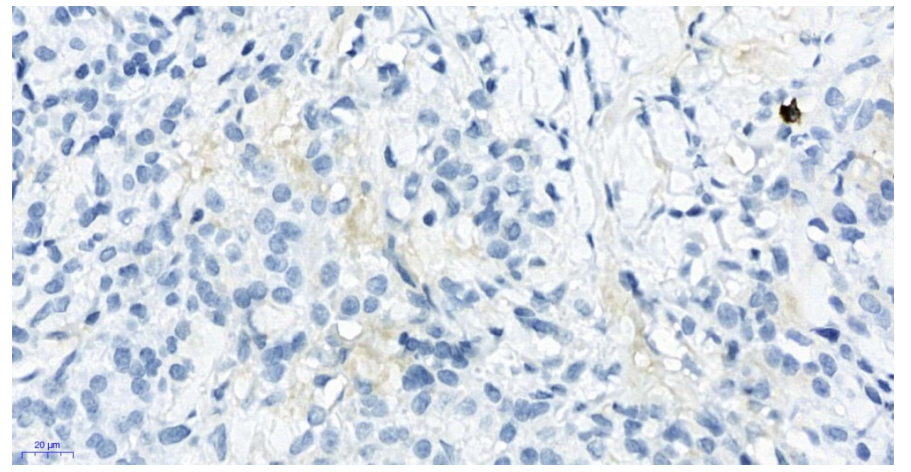

Figure 2e. Neoplastic cells are negative with lambda; only one plasma cell is positive in this area. X40

$<5 \%$ of plasma cells at bone marrow biopsy

Lack of osteolytic lesions

Lack of hypercalcemia or kidney failure

Low levels of M protein if present

The association of solitary EMP of the thyroid gland with lymphocytic thyroiditis is known and $82 \%$ of patients show lymphocytic thyroiditis [7]. As was the case for our patient, the thyroid surrounding the neoplasm showed lymphocytic thyroiditis. Presence of atypical Hurthle cells and amyloid in the tumor may mimic medullary thyroid cancer which makes it difficult to make a diagnosis at the FNA [4]. Follicular neoplasm of Hurthle cells also share common cytomorphological features with plasmacytoma making it challenging in the differential diagnosis [6]. FNA may be confused with mucosaassociated lymphoid tissue (MALT) lymphoma as well [7]. Plasma cells in the thyroid are rare, so such a finding in frozen section examination should raise a suspicion of plasma cell neoplasm [6]. High positivity for CD20 brought lymphoplasmacytic lymphoma and MALT lymphoma with plasmacytoid differentiation into consideration in our patient. But neoplasm composed of monotonous cells with plasmacytoid morphology and also CD20 positive cells, negative for PAX5, weak CD45 staining, and negativity for CD21 and CD 23 supported plasmacytoma.

Clinical outcome of patients with localized disease is favorable. 10year overall survival rate is $70 \%$. The disease may progress to multiple myeloma in $11-30 \%$ of patients. This is more common in patients with SEP of bone. Patients should be followed for the development of MM [9]. Treatment of EMP remains controversial. Both surgery and radiotherapy alone are advocated. Chemotherapy may be used in combination in the treatment of the primary disease or in recurrences 
[3]. Effect of chemotherapy on the course of EMP is not detected which makes it a candidate for select patients [8]. Patients requiring bone marrow transplantation may benefit from alkylating agents (cyclophosphamide) $[8,10]$.

\section{Conclusion}

Solitary extramedullary plasmacytoma of the thyroid is a rare disease. Laboratory tests are not helpful in the diagnosis. It usually occurs on a background lymphocytic thyroiditis rendering it hard at FNA. Special attention must be carried out in the setting of plasma cells in the thyroid which is an unusual finding. Prognosis is favorable. Surgery and/or radiotherapy are the treatment of choice. Patients requiring autologous bone marrow transplantation may benefit from chemotherapy with alkylating agents. Follow-up is required for disease progression and development of multiple myeloma.

\section{References}

1. Mertens de Wilmars M, Knoops L, Sempoux C, Galant C, Geets X, et al. (2015) Solitary extramedullary plasmocytoma of the thyroid: a case report and histological approach to plasma cells infiltrate in the thyroid gland. Acta Clin Belg 70: 133-137. [Crossref]
2. McKenna R, Kyle R, Kuehl W, Harris N, Coupland R, et al. (2017) Plasma Cell Neoplasm. In: Swerdlow S, Campo E, Harris N, Jaffe E, Pileri S, Stein H, et al., editors. WHO Classif Tumours Haematop Lymphoid Tissues. Lyon: IARC Press p. 241-258.

3. Hassan MJ, Khans S, Pujani M, Jetley S, Raina PK, et al. (2014) Extramedullary plasmacytoma of the thyroid: report of a rare case. Blood Res 49: 280-283. [Crossref]

4. Bhat V, Shariff S, Reddy RAN (2014) Extramedullary plasmacytoma of thyroid - a mimicker of medullary carcinoma at fine needle aspiration cytology: A case report. $J$ Cytol p. 53-56. [Crossref]

5. Gochhait D, Govindarajalou R, Kar R, Rangarajan V, Dehuri P, et al. (2019) Plasmacytoma of thyroid clinically and morphologically mimicking primary thyroid carcinoma. Cytopathology 2019. p. 113-116. [Crossref]

6. Refai F, Gomaa W, Abdullah L (2020) A Case Report of Thyroid Plasmacytoma and Literature Update. J Microsc Ultrastruct pp. 75-79. [Crossref]

7. Patten DK, Fazel M, Dina R, Tolley N (2011) Solitary extramedullary plasmacytoma of the thyroid involved by papillary carcinoma: a case report and review of the literature. Endocr Pathol 22: 155-158. [Crossref]

8. Galieni P, Cavo M, Pulsoni A, Avvisati G, Bigazzi C, et al. (2000) Clinical outcome of extramedullary plasmacytoma. Haematologica 85 : 47-51. [Crossref]

9. Ridal M, Ouattassi N, Harmouch T, Amarti A, Alami MN (2012) Solitary extramedullary plasmacytoma of the thyroid gland. Case Rep Otolaryngol 2012: 282784. [Crossref]

10. Sahu KK, Singh P, Malhotra P, Srinivasan R (2019) Thyroid Plasmacytoma: A Rare Cause of Hoarseness of Voice. Indian J Nucl Med 34: 78-80. [Crossref]

Copyright: (C2021 Kaya H. This is an open-access article distributed under the terms of the Creative Commons Attribution License, which permits unrestricted use, distribution, and reproduction in any medium, provided the original author and source are credited. 